\title{
Inhibitory effect of emodin on fatty acid synthase, colon cancer proliferation and apoptosis
}

\author{
KYUNG HALEE ${ }^{1 *}$, MYUNG SUN LEE ${ }^{2 *}$, EUN YOUNG CHA ${ }^{2}$, JI YOUNG SUL ${ }^{1,3}$, \\ JIN SUN LEE ${ }^{1,3}$, JIN SU KIM ${ }^{1}$, JUN BEOM PARK ${ }^{1}$ and JI YEON KIM ${ }^{1,4}$ \\ ${ }^{1}$ Department of Surgery; ${ }^{2}$ Surgical Oncology Research Laboratory, \\ Biomedical Research Institute, Chungnam National University Hospital; ${ }^{3}$ Department of Surgery \\ and Research Institute for Medicinal Sciences; ${ }^{4}$ Department of Surgery and Cancer Research Institute, \\ Chungnam National University College of Medicine, Daejeon 301-721, Republic of Korea
}

Received January 13, 2016; Accepted January 3, 2017

DOI: $10.3892 / \mathrm{mmr} .2017 .6254$

\begin{abstract}
Fatty acid synthase (FASN) is a key anabolic enzyme for de novo fatty acid synthesis, which is important in the development of colon carcinoma. The high expression of FASN is considered a promising molecular target for colon cancer therapy. Emodin, a naturally occurring anthraquinone, exhibits an anticancer effect in various types of human cancer, including colon cancer; however, the molecular mechanisms remain to be fully elucidated. Cell viability was evaluated using a Cell Counting Kit-8 assay. The apoptosis rate of cells was quantified via flow cytometry following Annexin V/propidium iodide staining. FASN activity was measured by monitoring oxidation of nicotinamide adenine dinucleotide phosphate at a wavelength of $340 \mathrm{~nm}$, and intracellular free fatty acid levels were detected using a Free Fatty Acid Quantification kit. Western blot analysis and reverse transcription-polymerase chain reaction were used to detect target gene and protein expression. The present study was performed to investigate whether the gene expression of FASN and its enzymatic activity are regulated by emodin in a human colon cancer cell line. Emodin markedly inhibited the proliferation of HCT116 cells and a higher protein level of FASN was expressed, compared with that in SW480, SNU-C2A or SNU-C5 cells. Emodin significantly downregulated the protein expression of FASN in HCT116 cells, which was caused by protein degradation due to elevated protein ubiquitination. Emodin also inhibited intracellular FASN enzymatic activity and reduced
\end{abstract}

Correspondence to: Professor Ji Yeon Kim, Department of Surgery and Cancer Research Institute, Chungnam National University College of Medicine, 33 Munhwa-ro, Jung-gu, Daejeon 301-721, Republic of Korea

E-mail: jkim@cnu.ac.kr

${ }^{*}$ Contributed equally

Key words: colon cancer, fatty acid synthase, emodin the levels of intracellular free fatty acids. Emodin enhanced antiproliferation and apoptosis in a dose- and time-dependent manner. The combined treatment of emodin and cerulenin, a commercial FASN inhibitor, had an additive effect on these activities. Palmitate, the final product of the FASN reaction, rescued emodin-induced viability and apoptosis. In addition, emodin altered FASN-involved signaling pathways, including phosphatidylinositol 3-kinase/Akt and mitogen-activated protein kinases/extracellular signal-regulated kinases $1 / 2$. These results suggested that emodin-regulated cell growth and apoptosis were mediated by inhibiting FASN and provide a molecular basis for colon cancer therapy.

\section{Introduction}

Colon cancer is the leading cause of cancer-associated mortality worldwide, as >1,000,000 individuals are diagnosed with colorectal cancer annually, resulting in a mortality rate of $~ 715,000$ in 2010, compared with 490,000 in $1990(1,2)$. It is more common in developed countries, in which $>65 \%$ of cases are found (3). Colon cancer treatment options include a combination of surgery, radiation therapy and chemotherapy; however, options are limited for patients with advanced colon cancer. Therefore, the identification of novel therapeutic targets is important to develop a therapeutic strategy, which may improve survival rates.

Fatty acid synthase (FASN) is a multifunctional enzyme, which catalyzes fatty acid synthesis from acetyl-CoA, malonyl-CoA and nicotinamide adenine dinucleotide phosphate (NADPH) as a cofactor. FASN is the key enzyme for de novo long-chain fatty acid biosynthesis. In normal human tissues or cells, FASN is downregulated following the ingestion of a sufficient level of dietary fatty acids. However, several solid tumor and cell lines derived from these tumors overexpress FASN (4). The different expression levels of FASN between cancer and normal tissues suggest that FASN may be a potential target for cancer therapy (5). FASN relies on enzymatic activity for survival and proliferation in various types of human cancer (6). The pharmacological or genetic inhibition of FASN induces growth arrest and apoptosis in tumor cells (7-9). 
Emodin (1,3,8-trihydroxy-6-methylanthraquinone) is an anthraquinone found in certain plants and has been evaluated for its antiproliferative and apoptotic activities in various cancer cell lines, including breast (10), liver (11), lung (12), prostate (13) and cervical cancer (14), leukemia (15) and colon cancer (16). Emodin has an anticancer effect based on the suppression of migration, invasion and angiogenesis $(17,18)$. The underlying mechanism of the anticancer activities of emodin includes generating reactive oxygen species (12) and inhibiting the expression of casein kinase II (19), protein kinase C (20), extracellular-signal regulated kinase (ERK)1/2 (21), vascular endothelial growth factor (VEGF) receptor phosphorylation (22) and human epidermal growth factor 2 (HER2)/neu tyrosine kinase (23). However, the function of emodin in the FASN-induced toxicity of human colon cancer cells remains to be elucidated.

The present study investigated the effects of FASN on intracellular fatty acid biosynthesis in emodin-induced cytotoxicity. The findings suggested that emodin may be a novel FASN inhibitor and may assist in formulating a therapeutic strategy for colon cancer.

\section{Materials and methods}

Materials. Fetal bovine serum (FBS), Dulbecco's modified Eagle's medium (DMEM), RPMI-1640, and penicillin/streptomycin were obtained from HyClone ${ }^{\mathrm{TM}}$; GE Healthcare Life Sciences (South Logan, UT, USA). Trypsin-EDTA was from Gibco; Thermo Fisher Scientific, Inc. (Waltham, MA, USA). Antibodies targeting FASN (catalog no.3180), caspase 3 (catalog no. 9662), caspase 7 (catalog no. 9494), caspase 9 (catalog no. 9502), ubiquitin (catalog no. 3936), microtubule-associated protein 1A/1B-light chain 3 (LC3) (catalog no. 4108), Akt (catalog no. 9272), phosphorylated (p) Akt (Ser473) (catalog no. 9271), phosphatidylinositol 3-kinase (PI3K) (catalog no. 4292), pPI3K (p85Tyr458/p55Tyr199) (catalog no. 4228), ERK1/2 (catalog no.4695), pERK1/2 (Thr202/Tyr204) (catalog no. 9101), and $\beta$-actin (catalog no. 4967) were purchased from Cell Signaling Technology, Inc. (Danvers, MA, USA), and anti-GAPDH (catalog no. SC-25778) was from Santa Cruz Biotechnology, Inc. (Santa Cruz, CA, USA). Horseradish peroxidase-conjugated anti-rabbit antibody (catalog no. 554021) was from Transduction Lab (Lexington, KY, USA). Super Signal ${ }^{\circledR}$ West Pico Chemiluminescent substrate was purchased from Pierce; Thermo Fisher Scientific, Inc. The Cell Counting Kit-8 (CCK8) was from Dojindo Molecular Technologies, Inc. (Kumamoto, Japan). TRIzol reagent was from Invitrogen ${ }^{\mathrm{TM}}$; Thermo Fisher Scientific, Inc. The Free Fatty Acid Quantification Colorimetric kit was purchased from BioVision, Inc. (Milpitas, CA, USA). The EzWay Annexin V-FITC Apoptosis Detection kit was obtained from KomaBiotech, Inc. (Seoul, Korea). AccuPower ${ }^{\circledR}$ CycleScript RT PreMix(dT20) was purchased from Bioneer Corporation (Daejeon, Korea). Emodin, cerulenin, cycloheximide (CHX), NADPH, palmitic acid, acetyl-CoA, malonyl-CoA, DMSO and other reagents were purchased from Sigma-Aldrich; Merck Millipore (Darmstadt, Germany).

Cell culture. The HCT116 and SW480 human colon cancer cell lines were obtained from American Type Culture Collection
(Rockville, MD, USA), and cultured in RPMI-1640 containing $10 \% \mathrm{FBS}(\mathrm{v} / \mathrm{v})$ and penicillin $(100 \mathrm{U} / \mathrm{ml}) /$ streptomycin $(100 \mu \mathrm{g} / \mathrm{ml})$. The SNU-C2A and SNU-C5 cell lines were purchased from the Korean Cell Line Bank (Seoul, Korea) and were grown in DMEM supplemented with $10 \%$ FBS. The cells were maintained at $37^{\circ} \mathrm{C}$ in a humidified atmosphere of $95 \%$ air and $5 \% \mathrm{CO}_{2}$.

Cell viability assay. The cells were seeded at a density of $5 \times 10^{3}$ cells $/ \mathrm{ml}$ in 96 -well microplates and allowed to attach for $24 \mathrm{~h}$. Following treatment of emodin (10-50 $\mu \mathrm{M})$ and/or cerulenin $(100 \mu \mathrm{M})$ for $6-24 \mathrm{~h}$, cell cytotoxicity and/or proliferation were assessed using CCK8. Briefly, water-soluble tetrazolium salt, WST-8[2-(2-methoxy-4-nitrophenyl)-3(4-nitrophenyl)-5-(2,4-disulfophenyl)-2H-tetrazolium, monosodium salt], produces an orange water-soluble product, formazan. The quantity of formazan dye generated by dehydrogenases in the cells is directly proportional to the number of living cells. CCK8 $(10 \mu \mathrm{l})$ was added to each well and incubated for $3 \mathrm{~h}$ at $37^{\circ} \mathrm{C}$, following which cell proliferation and cytotoxicity were assessed by measuring the absorbance at $450 \mathrm{~nm}$ using a microplate reader. Three replicate wells were used for each experimental condition.

Western blot analysis. The cells were harvested using Trypsin-EDTA, washed twice with cold phosphate-buffered saline (PBS), lysed with lysis buffer containing $10 \mathrm{mM}$ Tris (pH 7.4), $150 \mathrm{mM} \mathrm{NaCl}, 1 \mathrm{mM}$ EDTA, $1 \%$ Triton $\mathrm{X}-100$, $0.5 \%$ NP-40, $1 \mathrm{mM}$ PI, $1 \mathrm{mM}$ DTT and $1 \mathrm{mM}$ PMSF, and placed on ice for $1 \mathrm{~h}$ with occasional vortexing. Centrifugation followed at $13,000 \mathrm{x} \mathrm{g}$ for $10 \mathrm{~min}$ at $4^{\circ} \mathrm{C}$ to collect the supernatant. A Pierce BCA Protein Assay kit (Pierce; Thermo Fisher Scientific Inc.) was used to determine the protein concentration. The cell lysate $(50 \mu \mathrm{g})$ was subjected to 6 or $10 \%$ SDS-polyacrylamide gel electrophoresis and transferred onto a polyvinylidene difluoride membrane in Tris-Glycine buffer (25 mM Tris, $200 \mathrm{mM}$ Glycine and 20\% methanol) for $2 \mathrm{~h}$ $(60 \mathrm{~V})$. The blots were blocked with $5 \%$ skim milk in PBS containing $0.05 \%$ Tween-20 for $1 \mathrm{~h}$ at $25^{\circ} \mathrm{C}$ and were then incubated with primary antibodies $(1: 1,000)$ overnight at $4^{\circ} \mathrm{C}$, followed by incubation with anti-rabbit horseradish peroxidase-conjugated $\operatorname{IgG}(1: 3,000)$ for $2 \mathrm{~h}$ at room temperature and visualized with enhanced chemiluminescence.

RNA isolation and reverse transcription-polymerase chain reaction (RT-PCR) analysis. Following drug treatment, the cells were subjected to total RNA isolation using TRIzol, according to the manufacturer's protocol. The RNA concentrations were determined by measuring the absorption at $260 \mathrm{~nm}$ in a spectrophotometer. Aliquots of $1 \mu \mathrm{g}$ total RNA from each sample were reverse transcribed into cDNA in a total volume of 20 ul using AccuPower ${ }^{\circledR}$ CycleScript RT PreMix (dT20) according to the manufacturer's protocol. The PCR primers (10 pM) used in the present study were as follows: FASN, forward 5'-CTTGCAGGAGTTCTGGGACA and reverse 5'-CCGTCCACGATGGCTTCATA; GAPDH, forward 5'-TAG ACGGGAAGCTCACTGGC-3' and reverse 5'-AGGTCCACC ACCCTGTTGCT-3'. The PCR reactions were subjected to the following amplification conditions: denaturation at $94^{\circ} \mathrm{C}$ for $30 \mathrm{sec}$, annealing at $60^{\circ} \mathrm{C}$ for $30 \mathrm{sec}$ and extension at $68^{\circ} \mathrm{C}$ for 
60 sec. FASN and GAPDH were incubated for 40 cycles. The PCR products $(10 \mu \mathrm{l})$ were separated on a $1 \%$ agarose gel and detected using ethidium bromide staining.

FASN activity assay. Following exposure to emodin and/or cerulenin, cells were harvested and suspended with cold PBS. The cells were sonicated at $4^{\circ} \mathrm{C}$ and centrifuged at $15,000 \mathrm{x} g$ for 30 min to obtain particle-free supernatants. FASN activity was determined spectrophotometrically by measuring the decrease of absorption at $340 \mathrm{~nm}$ due to the oxidation of NADPH, as previously described (24). Particle-free supernatant $(20 \mu \mathrm{l})$, $25 \mathrm{mM} \mathrm{KH}_{2} \mathrm{PO}_{4}-\mathrm{K}_{2} \mathrm{HPO}_{4}$ buffer, $0.25 \mathrm{mM}$ EDTA, $0.25 \mathrm{mM}$ dithiothreitol, $30 \mu \mathrm{M}$ acetyl-CoA and $350 \mu \mathrm{M}$ NADPH (pH 7.0) in a total volume of $200 \mu 1$ were monitored at $340 \mathrm{~nm}$ for $5 \mathrm{~min}$ to measure background NADPH oxidation. Following the addition of $100 \mu \mathrm{M}$ of malonyl-CoA, the reaction was assayed for an additional 3 min to determine FASN-dependent oxidation of NADPH at $340 \mathrm{~nm}$ again.

Free fatty acid quantification assay. Following treatment of cells with emodin and/or cerulenin at the corresponding concentration and for the indicated durations, the cells were harvested and washed twice with cold PBS. The levels of intracellular free fatty acids were measured in the cells using a Free Fatty Acid Quantification Colorimetric kit according to the manufacturer's protocol. The samples were measured against a standard of varying concentrations of palmitic acid (provided by the kit) and the optical density was measured at $570 \mathrm{~nm}$ in a 96-well microplate reader (VersaMax ELISA microplate reader; VersaMax; Molecular Devices, Sunnyvale, CA, USA). The levels of free fatty acid in the samples were calculated using the slope of the standard curve, with the concentration expressed as $\mathrm{nmol} / \mu \mathrm{l}$.

Annexin V/propidium iodide staining. The cells were cultured at a $10^{6}$ density and treated with emodin and/or or cerulenin for $24 \mathrm{~h}$. The cells were centrifuged and washed three times with PBS. The supernatant was discarded and resuspended in $0.5 \mathrm{ml}$ of cold PBS. The cells were processed and labeled according to the EzWay Annexin V-FITC Apoptosis Detection kit used for this assay. The labeled cells were analyzed in a flow cytometer (BD FACSCanto ${ }^{\mathrm{TM}}$ II; BD Biosciences, Franklin Lakes, NJ, USA).

Flow cytometric analysis. The cells $\left(1 \times 10^{5}\right.$ cells $\left./ \mathrm{ml}\right)$ were suspended in $300 \mu \mathrm{l}$ PBS to which $700 \mu \mathrm{l}$ ethanol was added. The cells were incubated at $4^{\circ} \mathrm{C}$ for $1 \mathrm{~h}$, washed with PBS and suspended in $250 \mu \mathrm{l}$ of $1.12 \%$ sodium citrate buffer $(\mathrm{pH} 8.4)$ together with $12.5 \mu \mathrm{g}$ RNase. Incubation was continued at $37^{\circ} \mathrm{C}$ for $30 \mathrm{~min}$. The cellular DNA was stained by applying $250 \mu \mathrm{l}$ propidium iodide $(50 \mu \mathrm{g} / \mathrm{ml})$ for $30 \mathrm{~min}$ at room temperature. The stained cells were analyzed by fluorescent activated cell sorting on the BD FACSCanto ${ }^{\text {TM }}$ II flow cytometer using BD FACSDiva $^{\mathrm{TM}}$ Software v. 6. 1.3 (BD Biosciences) to determine the percentage of apoptotic cells.

\section{Results}

Emodin inhibits cell proliferation in human colon cancer cell lines. Several colon cancer cell lines (HCT116, SW480,
SNU-C2A and SNU-C5) were treated with emodin for $24 \mathrm{~h}$ to determine its effect on cell proliferation (Fig. 1A). Emodin exerted a significant dose-dependent antiproliferative effect in the HCT116 cell line (30.4 and $24.2 \%$ reduction at concentrations of 25 and $50 \mu \mathrm{M}$, respectively; Fig. 1A). Among the cell lines, HCT116 cells expressed the highest protein level of FASN, whereas SW480, SNU-C2A and SNU-C5 cells expressed lower protein levels of FASN (Fig. 1B). The results of the western blot analysis showed that emodin downregulated the protein expression of FASN, particularly in the HCT-116 cells, moderately downregulated expression in the SNU-C5 cells, and had no effect in the SW480 or SNU-C2A cells (Fig. 1C). Cell proliferation decreased and the expression of FASN was downregulated in SW480 cells following exposure to emodin for $48 \mathrm{~h}$ (data not shown). This result showed that emodin-induced cell death may be associated with the overexpression of FASN.

Emodin suppresses the protein level of FASN in HCT116 cells. Emodin $(25$ and $50 \mu \mathrm{M})$ significantly downregulated the protein expression of FASN in HCT116 cells (Fig. 1C). The HCT116 cells were then treated with emodin and the expression of FASN was measured over time (0-24 h). The protein levels of FASN decreased following exposure to emodin for $6 \mathrm{~h}$ and were significantly decreased at $24 \mathrm{~h}$ (Fig. 2A). The mRNA level of FASN also decreased following emodin treatment; however, the effect on protein was more marked, compared with that on mRNA (Fig. 2A). CHX, an inhibitor of de novo protein synthesis, was added during emodin $(25 \mu \mathrm{M})$ exposure to examine whether emodin regulates degradation of the FASN protein in HCT116 cells. Degradation of the FASN protein increased with an additive effect in the presence of emodin and CHX (Fig. 2B). Protein degradation is usually triggered by ubiquitin moieties attaching to protein. Therefore, the present study examined whether emodin induced protein ubiquitination in the HCT116 cells. The results showed that emodin induced the accumulation of ubiquitinated proteins (Fig. 2C), and MG-132 was used as a potent proteasome inhibitor. Whether emodin stimulated lysosomal activity was also examined. Emodin did not convert LC3-I to the smaller form, LC3-II, which is an autophagy marker (Fig. 2D). This result suggested that emodin induced the degradation of FASN protein caused by increased protein ubiquitination activity.

Emodin inhibits intracellular FASN activity and intracellular free fatty acids. A high expression level of FASN is a molecular change associated with colon cancer. In the present study, the cells were incubated with $25 \mu \mathrm{M}$ emodin and/or the FASN inhibitor cerulenin $(100 \mu \mathrm{M})$ for $24 \mathrm{~h}$ to evaluate cellular FASN activity. Emodin reduced cellular FASN activity in the HCT116 cells to $39.2 \%$, cerulenin reduced FASN activity to $60.4 \%$ and the two in combination reduced FASN activity to $53.8 \%$ (Fig. 3A). The overexpression of FASN in several types of cancer markedly induces de novo lipogenesis, including phospholipids, which are necessary for de novo synthesis of the cell membrane (25). Thus, inhibiting FASN can reduce the levels of phospholipids and free fatty acids required (26). The present study measured free fatty acids using a Free Fatty Acid Quantification lit, as the primary function of FASN is to 
A

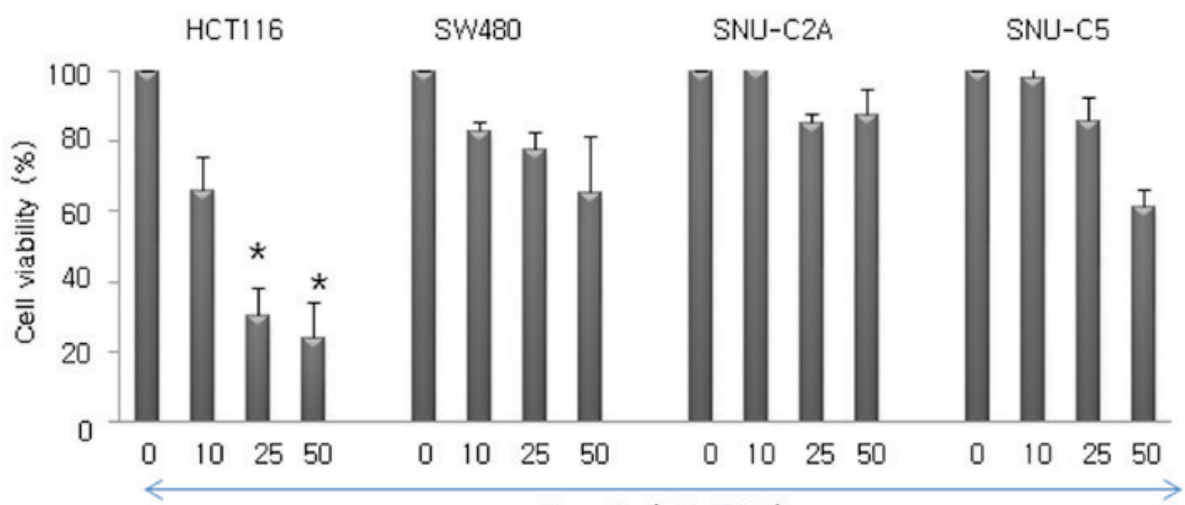

B

Emodin $(\mu \mathrm{M}, 24 \mathrm{~h})$
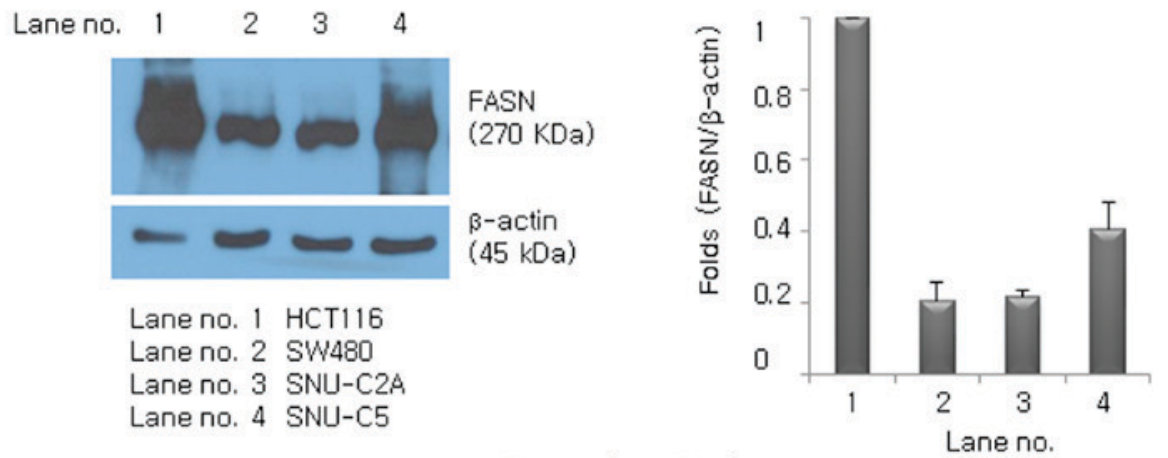

C

Emodin $(\mu \mathrm{M}, 24 \mathrm{~h})$
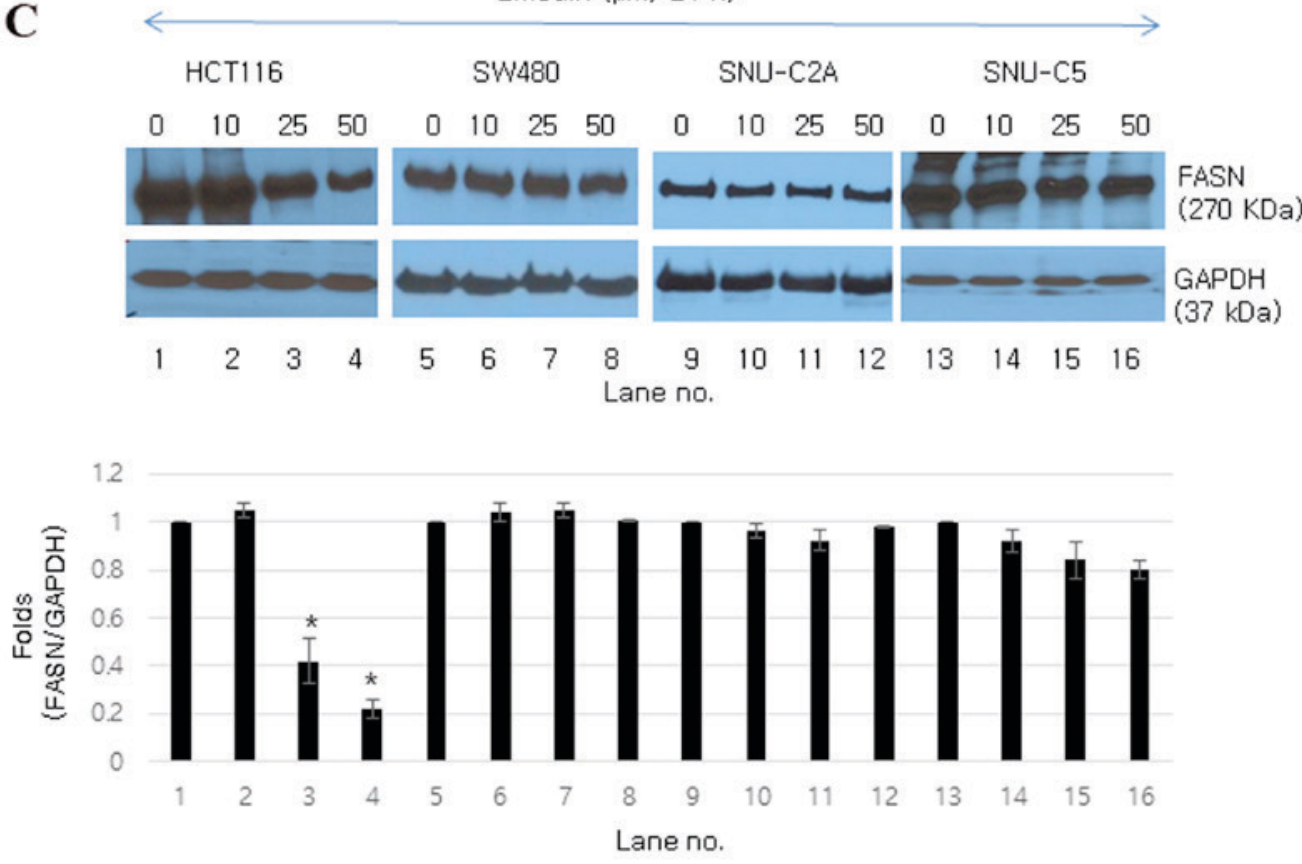

Figure 1. Emodin inhibits proliferation of human colon cancer cell lines. (A) Emodin inhibited growth of HCT116, SW480, SNU-C2A and SNU-C5 human colon cancer cell lines. Data are presented as the mean \pm standard deviation of triplicate determinations. " $\mathrm{P}<0.05$, vs. control $(0 \mu \mathrm{M})$. (B) Protein expression levels of FASN in HCT116, SW480, SNU-C2A and SNU-C5 human colon cancer cells. $\beta$-actin (45 kDa) was used as the loading control. (C) Emodin-induced protein expression levels of FASN at various concentrations $(0,10,25$ and $50 \mu \mathrm{M})$ in HCT116, SW480, SNU-C2A and SNU-C5 human colon cancer cell lines. GAPDH was used as the loading control. "P<0.05 vs. control. FASN, fatty acid synthase; GAPDH, glyceraldehyde 3-phosphate dehydrogenase.

catalyze long-chain fatty acid biosynthesis. Emodin treatment reduced the level of intracellular free fatty acids (Fig. 3B). The emodin-induced $(25 \mu \mathrm{M})$ FASN inhibitory activities were more marked, compared with those of cerulenin $(100 \mu \mathrm{M})$ in HCT116 cells. These results indicated that emodin inhibited FASN function.
Combined treatment with emodin and cerulenin has an additive effect on cell growth and apoptosis. To assess whether the FASN inhibitor, cerulenin, enhances the emodin-induced expression of FASN in HCT116 cells, the cells were incubated with emodin $(25 \mu \mathrm{M})$ and/or cerulenin $(100 \mu \mathrm{M})$ for $24 \mathrm{~h}$. The combined treatment of emodin and cerulenin decreased the 
A
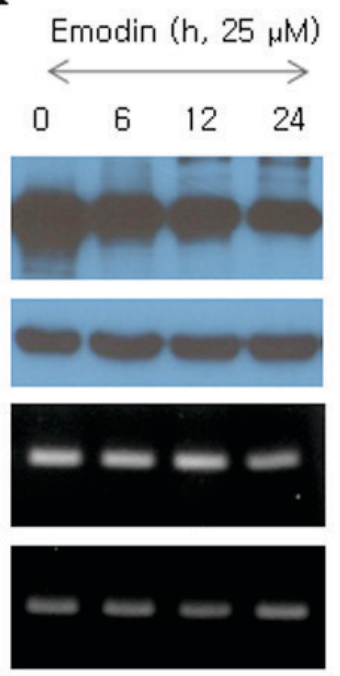

FASN (270 kDa)

$\mathrm{GAPDH}$ (37 kDa)

FASN (226 bp)

GAPDH (163 bp)

B

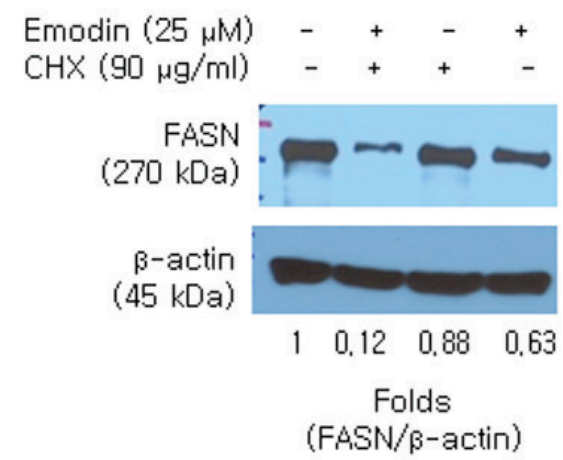

D

Emodin (h, $25 \mu \mathrm{M})$
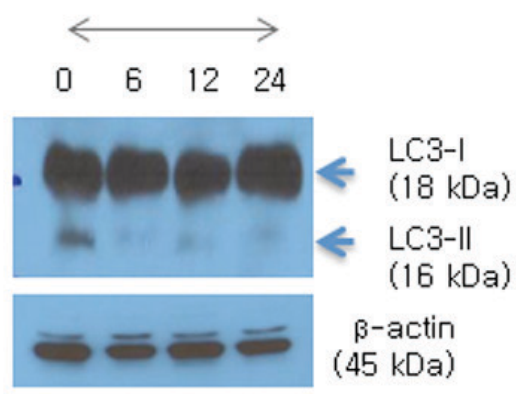

Protein expression

mRNA expression

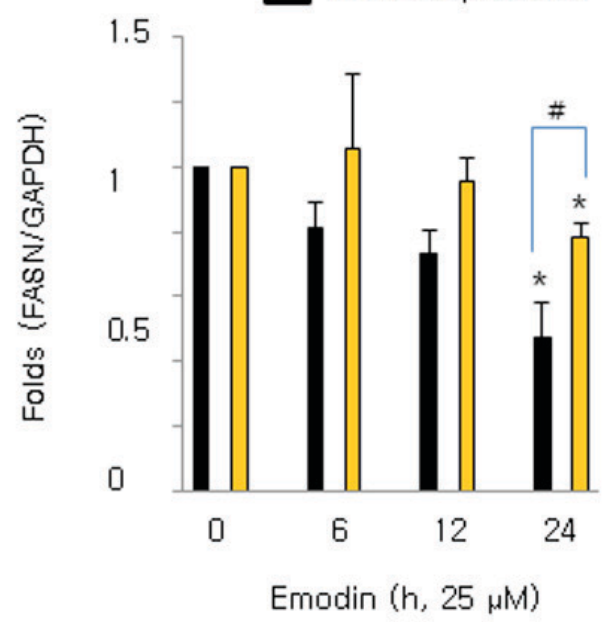

C
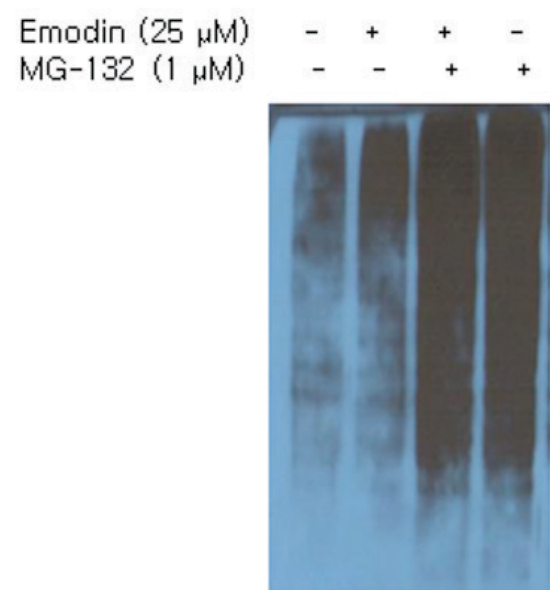

Ubiquitin

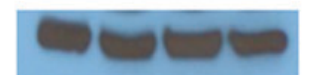

$\beta$-actin (45 kDa)

$\begin{array}{llll}1 & 2.38 & 17.81 & 12.4\end{array}$

Folds (ubiquitin/ $\beta$-actin)

Figure 2. Emodin decreases protein expression of FASN. (A) HCT116 cells were exposed to emodin (25 $\mu \mathrm{M})$ for 0-24 h. Western blot and reverse transcription-polymerase chain reaction analyses were used to measure protein and mRNA expression levels of FASN. GAPDH was used as the loading control. ${ }^{\mathrm{P}}<0.05$ vs. control. " $\mathrm{P}<0.05$ vs. mRNA expression level. (B) Cells were exposed to emodin $(25 \mu \mathrm{M}), \mathrm{CHX}(90 \mu \mathrm{g} / \mathrm{ml})$, or a combination of emodin and CHX, and the protein expression level of FASN was determined using western blot analysis. $\beta$-actin was used as the loading control. (C) HCT116 cells were treated with emodin $(25 \mu \mathrm{M})$ and/or MG-132 $(1 \mu \mathrm{M})$. Whole cell lysates were subjected to sodium docecyl sulfate-polyacrylamide gel electrophoresis followed by western blot analysis using antibodies specific for ubiquitin and $\beta$-actin. (D) Cells were exposed to emodin (25 $\mu \mathrm{M})$ for 6,12 and $24 \mathrm{~h}$ and subjected to western blot analysis to detect the conversion of LC3-I into autophagosome-associated LC3-II. $\beta$-actin was used as the loading control. FASN, fatty acid synthase; GAPDH, glyceraldehyde 3-phosphate dehydrogenase; CHX, cycloheximide; LC3, microtubule-associated protein 1A/1B-light chain 3.

protein expression of FASN, compared with either treatment alone (Fig. 4A). To determine whether cerulenin enhanced emodin-induced anticancer effects in HCT116 cells, the cells were incubated with different concentrations of emodin $(10$ and $25 \mu \mathrm{M})$ for various durations $(6,12$ and $24 \mathrm{~h})$, with or without cerulenin $(100 \mu \mathrm{M})$, and performed a CCK8 assay. Emodin exhibited cytotoxic effects in a dose-and time-dependent manner. The combination of emodin and cerulenin induced higher antiproliferative effects, compared with those of emodin or cerulenin alone (Fig. 4B and C). The induction 
A

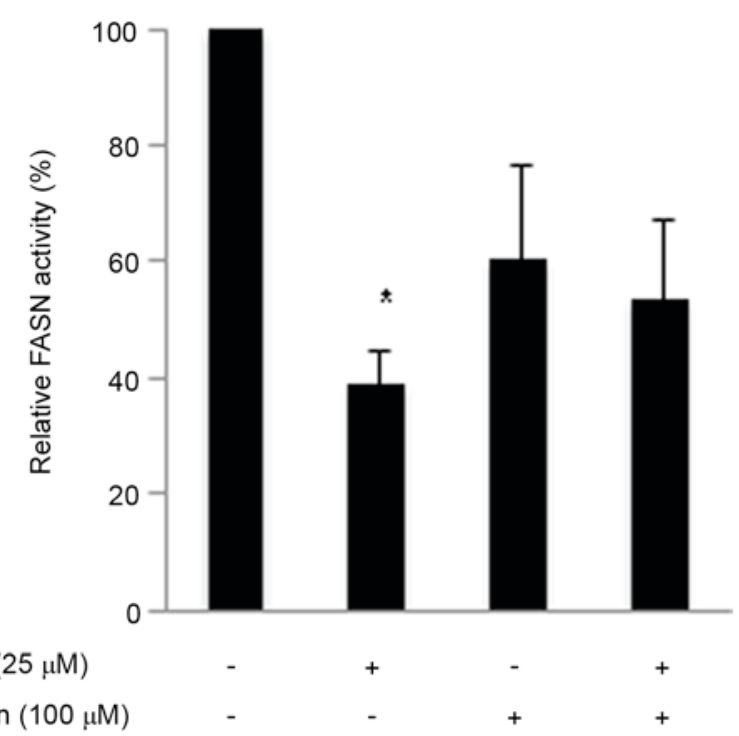

B

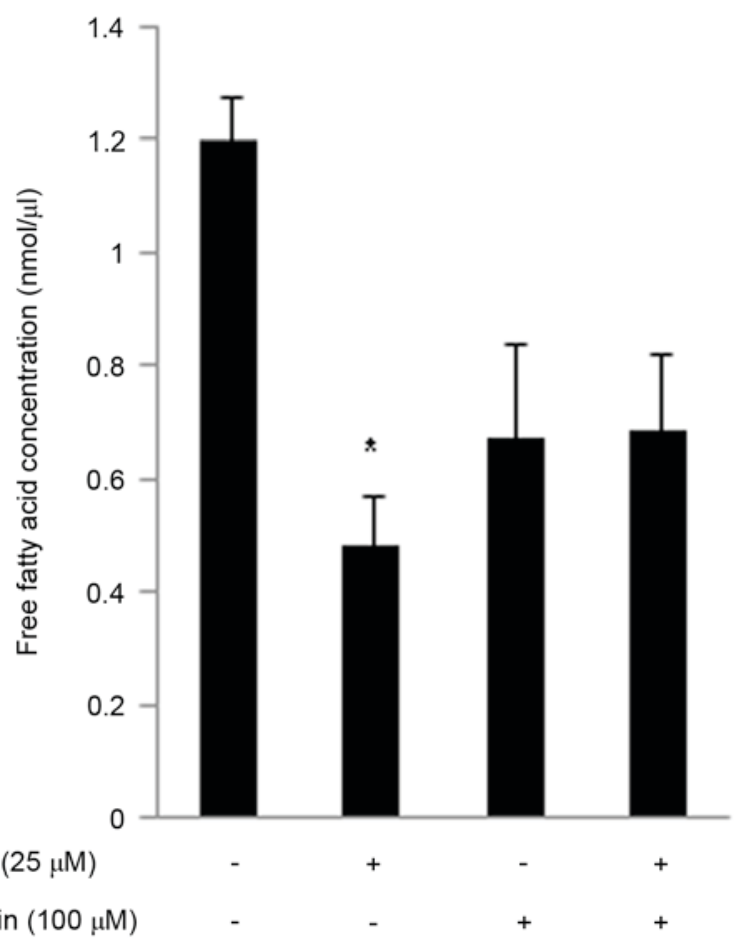

Figure 3. Emodin decreases the effects of FASN. (A) Inhibition of FASN by emodin and/or cerulenin were measured. Relative FASN activity was measured spectrophotometically by monitoring oxidation of nicotinamide adenine dinucleotide phosphate at $340 \mathrm{~nm}$. Values are presented as the mean \pm standard deviation of triplicate determinations. ${ }^{*} \mathrm{P}<0.05$, vs. control. (B) Intracellular free fatty acid levels were detected using a Free Fatty Acid Quantification kit following treatment with emodin and/or cerulenin. Free fatty acid concentration $(\mathrm{nmol} / \mu \mathrm{l})$ is presented as the mean + standard deviation of triplicate determinations. ${ }^{*} \mathrm{P}<0.05$, vs. control. Cerulenin is a natural FASN inhibitor and was used as the positive control. FASN, fatty acid synthase.

of apoptosis by emodin and/or cerulenin was concordant with the cell viability results. Apoptosis was determined using Annexin V/propidium iodide double staining (Fig. 4D) and caspase cleavage (Fig. 4E) following exposure of emodin $(25 \mu \mathrm{M})$ and/or cerulenin $(100 \mu \mathrm{M})$ for $24 \mathrm{~h}$. The apoptotic effect of emodin and cerulenin in combination was higher, compared with apotosis induced by emodin or cerulenin alone. These results suggested that the emodin-induced inhibition of FASN enhanced antiproliferation and apoptosis.

Palmitate rescues emodin-induced apoptosis and viability. In the present study, cells were also treated with emodin and palmitate $(75 \mu \mathrm{M})$, the end product of the FASN reaction, to determine whether the emodin-induced cell death activities were associated with inhibiting FASN. In the presence of palmitate, emodin-induced decreased cell viability was increased (Fig. 5A). Propidium iodide staining was used to measure the number of apoptotic cells by flow cytometry. Addition exogenous palmitate reduced the level of emodin-induced apoptosis (Fig. 5B). These results suggested that emodin-stimulated cytotoxicity was regulated by fatty acid synthesis.

Emodin alters PI3K/Akt and ERK1/2 phosphorylation by inhibiting FASN. The PI3K/Akt and MAPK/ERK1/2 cascades are involved in cell proliferation, survival and apoptosis associated with FASN regulation in cancer (27-29). The present study examined the effect of inhibiting FASN by emodin on PI3K/Akt and ERK1/2 phosphorylation. Inhibiting FASN caused a time-dependent decrease in PI3K/Akt phosphorylation and increase in ERK1/2 phosphorylation in the HCT116 cells (Fig. 6A). The combined treatment with cerulenin enhanced these activities (Fig. 6A). LY294002 (PI3K inhibitor) or PD98059 (ERK inhibitor) were added with the emodin to determine whether these two pathways regulated the emodin-induced inhibition of FASN. The inhibitors altered the phosphorylation of PI3K/Akt and ERK modulated by emodin (Fig. 6B and C). These data indicated that the PI3K/Akt and ERK1/2 signaling pathways regulated the reduced expression of FASN induced by emodin.

\section{Discussion}

Different expression levels of FASN between cancerous and normal cells have been suggested as a potential target for anticancer drug development (4). FASN has been implicated in breast cancer predominantly through its connection with the activity of HER2 in transcriptional, proteomic and functional analyses $(8,30,31)$. The expression of FASN also appears to be important in cell growth and pathogenesis in colon cancer (32). FASN is expressed in all colorectal neoplasms and there is a concomitant increase in fatty acid synthesis (32). The overexpression of FASN by tumors is associated with improved survival rates of patients with colon cancer (33), and high serum levels of FASN in patients with colorectal cancer are associated with tumor events, lymph node metastasis status, distant metastasis and tumor clinical stage (5). It has been suggested that inhibiting FASN pharmacologically reduces cell growth and survival, and induces the apoptosis of colon cancer cells (34). For example, cerulenin, a natural FASN inhibitor, enhances antitumor activity when combined with oxaliplatin in human colon cancer cells (35) and suppresses liver metastasis of colon cancer (36). C75, a stable synthetic small molecule developed specifically for inhibiting FASN, produces a cytotoxic effect modulated by p53 in colon carcinoma cells (37). Naturally occurring olive oil polyphenols have the ability to suppress FASN, providing a well-tolerated 
A Emodin $(25 \mu \mathrm{M}) \quad-\quad+\quad-\quad+\quad+$
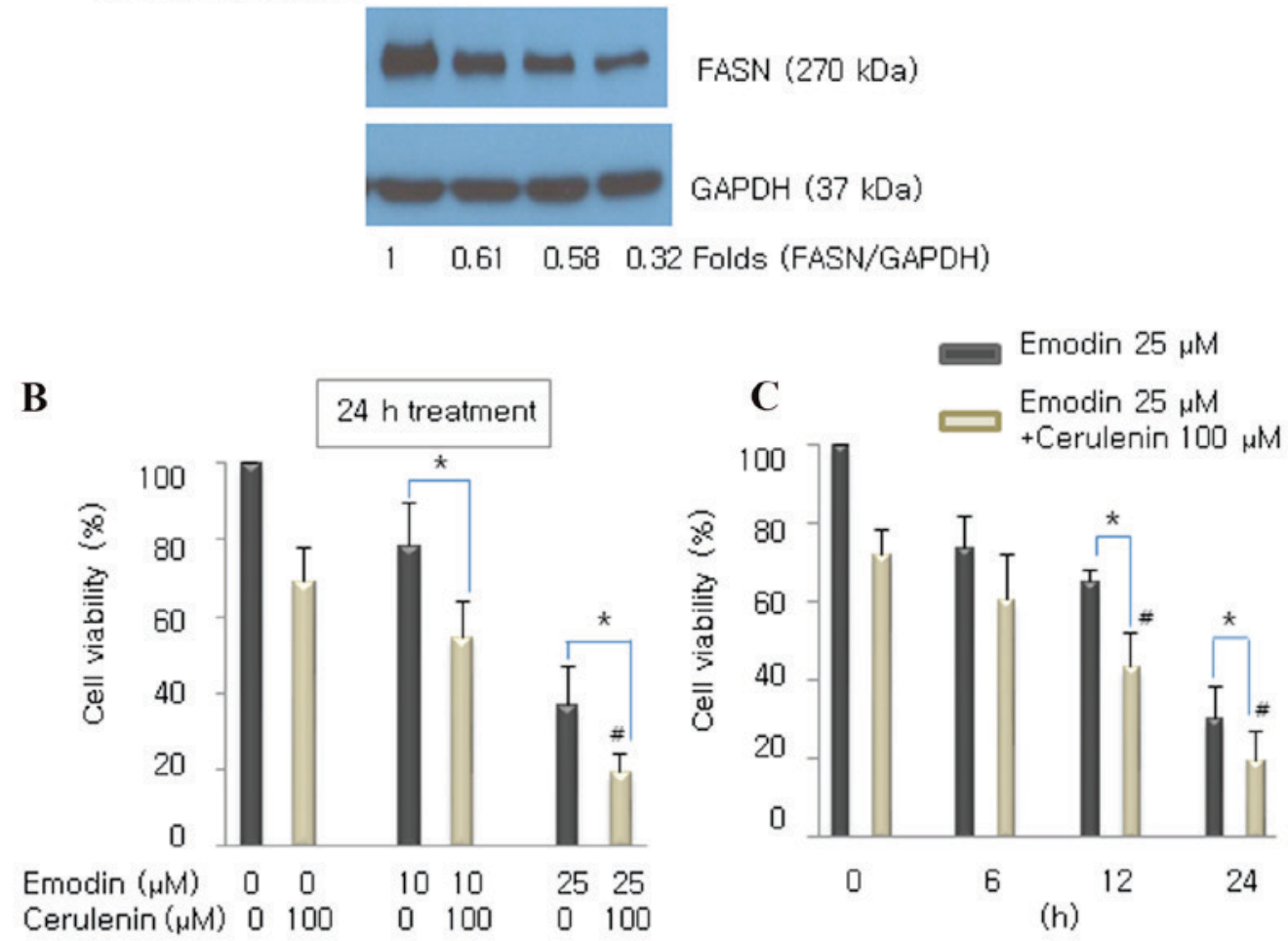

D Apoptotic

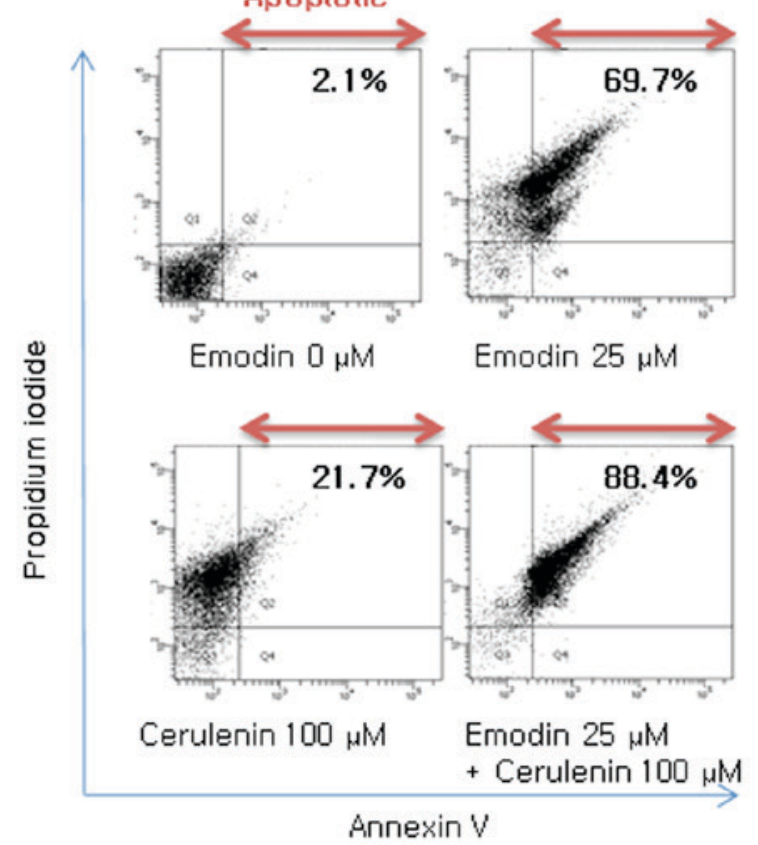

E
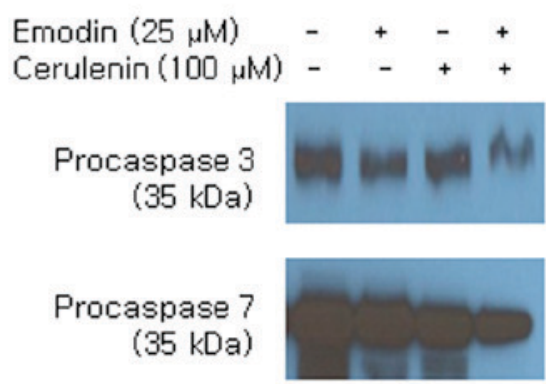

Procaspase 9

$(47 \mathrm{kDa})$

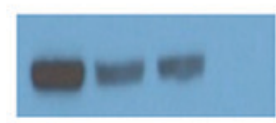

GAPDH

$(37 \mathrm{kDa})$

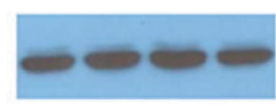

Figure 4. Emodin combined with the FASN inhibitor cerulenin enhances antiproliferation and apoptosis, compared with the effect of either drug alone. (A) Expression of FASN was measured using western blot analysis following treatment with emodin $(25 \mu \mathrm{M})$, cerulenin (100 $\mu \mathrm{M})$ or the two in combination. Cells were incubated with (B) 10 and $25 \mu \mathrm{M}$ emodin for (C) 6,12 and $24 \mathrm{~h}$, with or without $100 \mu \mathrm{M}$ cerulenin. Cell viability was determined using a Cell Counting Kit 8 assay. Values are presented as the mean \pm standard deviation of triplicate determinations. ${ }^{*} \mathrm{P}<0.05$ vs. emodin single treatment. ${ }^{*} \mathrm{P}<0.05$, vs. cerulenin single treatment. (D) Following treatment, the cells were double stained with Annexin V/propidium iodide and analyzed by flow cytometry. The gate setting distinguished between living (bottom left), necrotic (top left), early apoptotic (bottom right) and late apoptotic (top right) cells. (E) Cleavage of caspase 3, 7 and 9 was determined using western blot analysis following treatment with emodin $(25 \mu \mathrm{M})$, cerulenin $(100 \mu \mathrm{M})$, and the two combined for $24 \mathrm{~h}$. GAPDH was used as the loading control. FASN, fatty acid synthase; GAPDH, glyceraldehyde 3-phosphate dehydrogenase.

novel colon cancer therapy (38). However, no studies have reported that emodin has FASN inhibitory activity in cancer. It has been suggested that emodin may be a fat-reducing drug by inhibiting FASN (39). The findings of the present study revealed for the first time, to the best of our knowledge, that emodin suppressed the protein expression of FASN and 


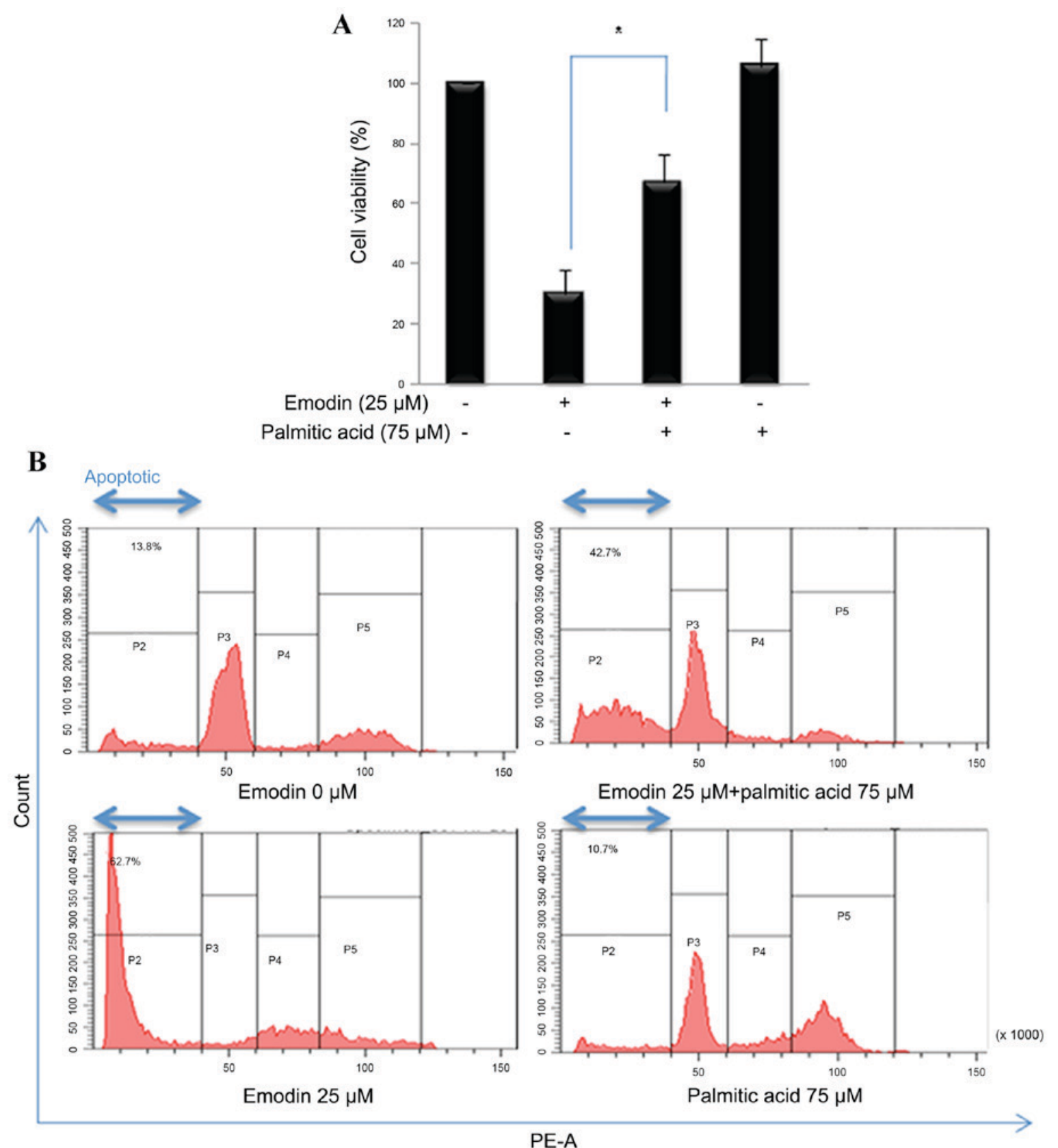

Figure 5. Sodium palmitate rescues emodin-induced apoptosis and antiproliferation. Cells were treated with emodin (25 $\mu \mathrm{M})$ in the presence of sodium palmitate $(75 \mu \mathrm{M})$. After $24 \mathrm{~h}$, cell viability was determined. A (A) Cell Counting Kit-8 assay and (B) propidium iodide staining were used to analyze cell proliferation and apoptosis, respectively. Values are presented as the mean \pm standard deviation. ${ }^{*} \mathrm{P}<0.05$, vs. control.

reduced its activity in human colorectal cancer cells. As shown in Fig. 1B, the HCT116 cell line had significantly elevated expression levels of FASN, compared with levels in the other colon cancer cell lines. This elevated expression of FASN in HCT116 cells was more effective in reducing cancer cell death following emodin treatment, compared with cells with a low expression level of FASN (Fig. 1A). Emodin only downregulated the expression of FASN in HCT116 cells (Fig. 1C), suggesting that emodin-induced cell death may be regulated by FASN-involved de novo fatty acid synthesis. These data suggested that inhibiting FASN may be an effective strategy for treating colon cancer overexpressing FASN.

Previous studies have demonstrated that emodin suppresses tumor growth in LS1034 human colon cancer cells in vitro and in vivo (40), induces apoptosis triggered by oxidative stress in colon cancer cells (16) and inhibits colon cancer cell growth by inhibiting VEGFR signaling (22). However, the molecular mechanisms underlying emodin-induced cell death in colorectal cancer cells have not been investigated in detail. Until now, no studies have reported the effect of emodin on the expression of FASN or its activity in cancer, including colorectal cancer. The present study found that emodin suppressed the expression of FASN by degrading FASN protein, which was caused by elevated protein ubiquitination, in HCT116 cells (Figs. 1C and 2). Tomek et al (9) reported that inhibiting FASN with $\mathrm{C} 75$ results in the accumulation of ubiquitinated proteins, including PI3K and MAPK signaling proteins, in ovarian cancer (9). Emodin also induces the proteosomal degradation 
A

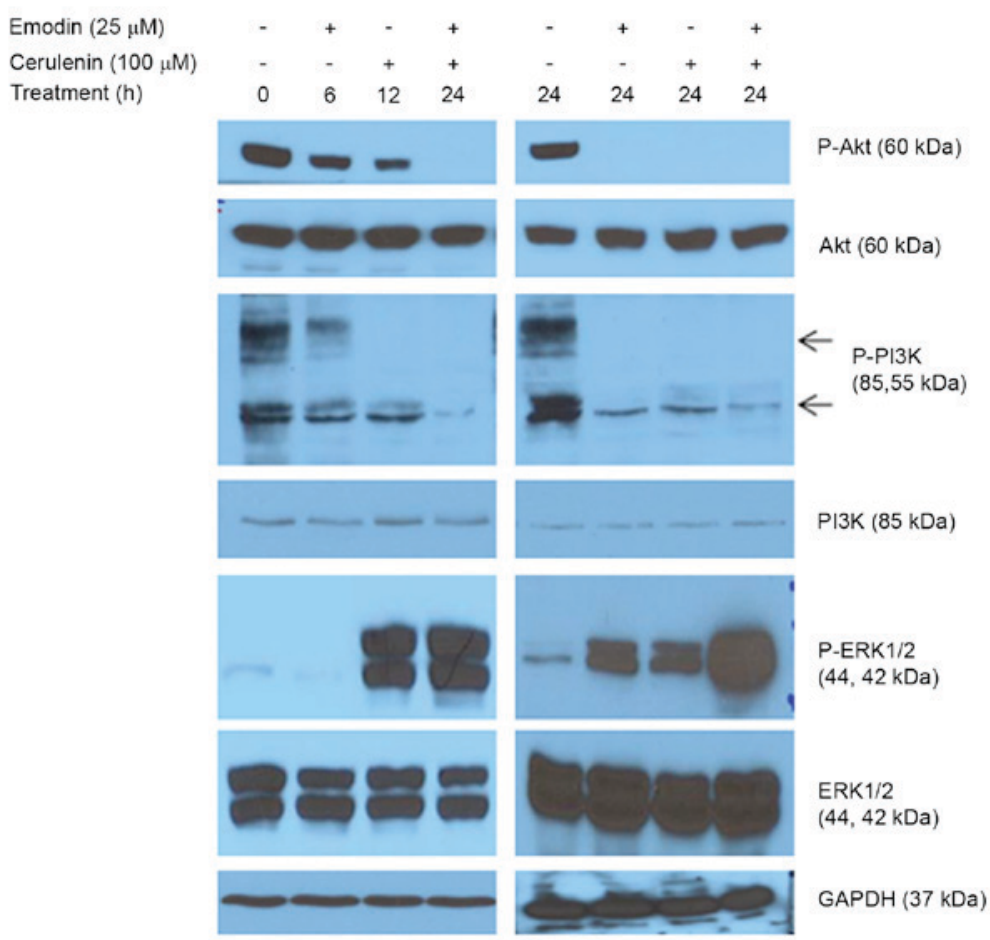

B

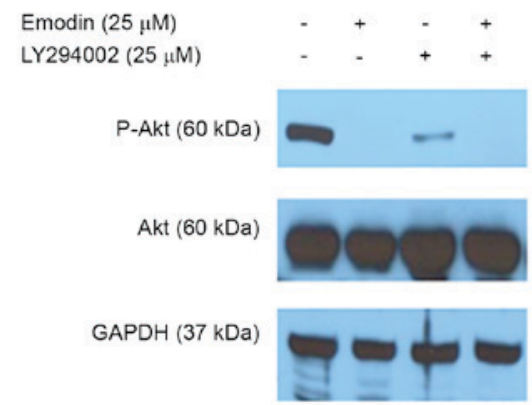

C

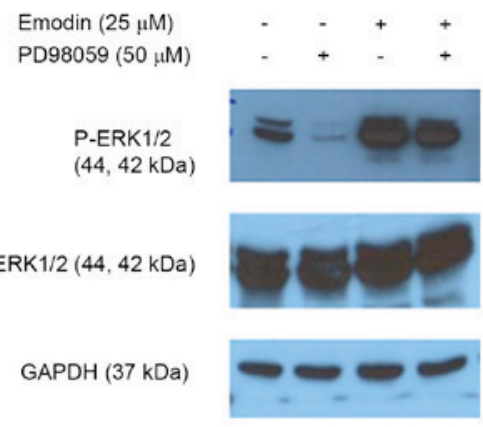

Figure 6. Emodin alters PI3K/AKT and ERK1/2 phosphorylation. (A) Following treatment with emodin and/or cerulenin for 6, 12 and $24 \mathrm{~h}$, the levels of AKT, P-AKT, PI3K, P-PI3K, ERK1/2 and P-ERK1/2 were determined using western blot analysis. (B) Following treatment with emodin and/or LY294002 (25 $\mu$ M), AKT and P-AKT (Ser473) were determined using western blot analysis. (C) Cells were treated with emodin (25 $\mu \mathrm{M})$ and/or PD98059 (50 $\mu \mathrm{M})$ as a selective ERK inhibitor for $24 \mathrm{~h}$, and equal quantities of lysates were immunoblotted with ERK1/2 and P-ERK1/2 (Thr202/Tyr204). GAPDH was used as the loading control. FASN, fatty acid synthase; GAPDH, glyceraldehyde 3-phosphate dehydrogenase; PI3K, phosphatidylinositol 3-kinase; ERK, extracellular-signal regulated kinase; P-, phosphorylated.

of EGFR/EGFR variant III in glioma stem cells (41). However, no previous study has reported that emodin induces the degradation of FASN protein.

In the present study, emodin concomitantly inhibited FASN activity and downregulated the protein expression of FASN (Fig. 3A and B). FASN is a key lipogenic enzyme. The overexpression of FASN in several types of cancer induces de novo lipogenesis, which is involved in cell survival, proliferation, migration and invasion (27). Therefore, downregulating the activity of FASN in cancer cells is necessary for tumor cell death. The present study determined concentrations of free fatty acids using a Free Fatty Acid Quantification kit (Fig. 3B). Emodin reduced the concentration of fatty acids, indicating that emodin inhibited the function of FASN in HCT116 cells.

FASN is essential for the proliferation and survival of human colorectal carcinoma cells, as demonstrated by the
FASN inhibitor, which reduces the cell growth and promotes apoptosis (42). The present study hypothesized that emodin induces colorectal cancer apoptosis by inhibiting the expression and function of FASN. It was shown that emodin produced a dose- and time-dependent decrease in HCT116 cell viability (Fig. 4B and C) and induced apoptosis, as shown by Annexin/propidium iodide double staining and caspase cleavage (Fig. 4D and E). It was also observed that cell viability and apoptosis were partially rescued following the addition of palmitate, which is the final product of FASN activity (Fig. 5A and B). Palmitate-induced toxicity has been reported in various cell lines; however, the present study demonstrated that exogenous palmitate and emodin treatment increased HCT116 cell viability. These results suggested that inhibiting FASN was a direct contributor to the anticancer effects of emodin on HCT116 colon cancer cells, and that fatty 
acid synthesis was closely associated with colon cancer cell death.

The PI3K/Akt and MAPK/ERK1/2 signaling pathways promote cell proliferation, survival and the anti-apoptotic response, and have been implicated in regulating the expression of FASN in cancer, including breast and ovarian cancer $(28,43)$. The level of FASN and activity of Akt are higher in HER2-positive cancer, and inhibiting fatty acid synthesis affects the HER2 and PI3K/Akt pathways (42). FASN is regulated in malignancies by growth factor-dependent signaling, which activates the Ras-Raf-MEK-ERK1/2 and PI3K/Akt pathways (44). The downregulation of PI3K/Akt phosphorylation can attenuate the expression of FASN (27). The FASN inhibitor, C75, inhibits pAkt, but increases pERK1/2 in ovarian cancer cells (7); the $\alpha$-mangostin-induced inhibition of FASN decreases pAkt, but increases active pERK1/2 in breast cancer cells (27). In the present study, it was found that emodin downregulated pPI3K and pAkt in a time-dependent manner (Fig. 6A). Emodin upregulated active levels of pERK1/2 in HCT116 cells (Fig. 6A). These data demonstrated that the emodin-induced inhibition of FASN may be associated with the PI3K/Akt and ERK1/2 signaling pathways in colorectal cancer.

The findings of the present study suggested that emodin downregulated the expression of FASN, inhibited intracellular FASN activity and fatty acid biosynthesis, and induced antiproliferation and apoptosis in HCT116 human colon cancer cells. Therefore, the results showed that emodin has therapeutic potential as a colon cancer treatment, and may provide a novel method in developing target-directed anticancer drugs for further investigations.

\section{Acknowledgements}

This study was supported by a research fund of Chungnam National University, Daejeon, Korea (grant no. 2013-2017).

\section{References}

1. Cunningham D, Atkin W, Lenz HJ, Lynch HT, Minsky B, Nordlinger B and Starling N: Colorectal cancer. Lancet 375: 1030-1047, 2010.

2. Lozano R, Naghavi M, Foreman K, Lim S, Shibuya K, Aboyans V, Abraham J, Adair T, Aggarwal R, Ahn SY, et al: Global and regional mortality from 235 causes of death for 20 age groups in 1990 and 2010: A systematic analysis for the global burden of disease study 2010. Lancet 380: 2095-2128, 2012.

3. Merika E, Saif MW, Katz A, Syrigos K and Morse M: Colon cancer vaccines: An update. In vivo 24: 607-628, 2010.

4. Kuhajda FP: Fatty acid synthase and cancer: New application of an old pathway. Cancer Res 66: 5977-5980, 2006.

5. Long QQ, Yi YX, Qiu J, Xu CJ and Huang PL: Fatty acid synthase (FASN) levels in serum of colorectal cancer patients: Correlation with clinical outcomes. Tumour Biol 35: 3855-3859, 2014.

6. Mounier C, Bouraoui L and Rassart E: Lipogenesis in cancer progression (review). Int J Oncol 45: 485-492, 2014.

7. Grunt TW, Wagner R, Grusch M, Berger W, Singer CF, Marian B, Zielinski CC and Lupu R: Interaction between fatty acid synthase- and ErbB-systems in ovarian cancer cells. Biochem Biophys Res Commun 385: 454-459, 2009.

8. Lee JS, Sul JY, Park JB, Lee MS, Cha EY, Song IS, Kim JR and Chang ES: Fatty acid synthase inhibition by amentoflavone suppresses HER2/neu (erbB2) oncogene in SKBR3 human breast cancer cells. Phytother Res 27: 713-720, 2013.

9. Tomek K, Wagner R, Varga F, Singer CF, Karlic H and Grunt TW: Blockade of fatty acid synthase induces ubiquitination and degradation of phosphoinositide-3-kinase signaling proteins in ovarian cancer. Mol Cancer Res 9: 1767-1779, 2011.
10. Huang Z, Chen G and Shi P: Effects of emodin on the gene expression profiling of human breast carcinoma cells. Cancer Detect Prev 32: 286-291, 2009.

11. Hsu CM, Hsu YA, Tsai Y, Shieh FK, Huang SH, Wan L and Tsai FJ: Emodin inhibits the growth of hepatoma cells: Finding the common anti-cancer pathway using Huh7, Hep3B, and HepG2 cells. Biochem Biophys Res Commun 392: 473-478, 2010.

12. Lai JM, Chang JT, Wen CL and Hsu SL: Emodin induces a reactive oxygen species-dependent and ATM-p53-Bax mediated cytotoxicity in lung cancer cells. Eur J Pharmacol 623: 1-9, 2009.

13. Cha TL, Qiu L, Chen CT, Wen Y and Hung MC: Emodin down-regulates androgen receptor and inhibits prostate cancer cell growth. Cancer Res 65: 2287-2295, 2005.

14. Srinivas G, Anto RJ, Srinivas P, Vidhyalakshmi S, Senan VP and Karunagaran D: Emodin induces apoptosis of human cervical cancer cells through poly(ADP-ribose) polymerase cleavage and activation of caspase-9. Eur J Pharmacol 473: 117-125, 2003.

15. Chun-Guang W, Jun-Qing Y, Bei-Zhong L, Dan-Ting J, Chong W, Liang Z, Dan Z and Yan W: Anti-tumor activity of emodin against human chronic myelocytic leukemia K562 cell lines in vitro and in vivo. Eur J Pharmacol 627: 33-41, 2010.

16. Xie MJ, Ma YH, Miao L, Wang Y, Wang HZ, Xing YY, Xi T and Lu YY: Emodin-provoked oxidative stress induces apoptosis in human colon cancer HCT116 Cells through a p53-mitochondrial apoptotic pathway. Asian Pac J Cancer Prev 15: 5201-5205, 2014.

17. Lin SZ, Wei WT, Chen H, Chen KJ, Tong HF, Wang ZH, Ni ZL, Liu HB, Guo HC and Liu DL: Antitumor activity of emodin against pancreatic cancer depends on its dual role: Promotion of apoptosis and suppression of angiogenesis. PLoS One 7: e42146, 2012.

18. Manu KA, Shanmugam MK, Ong TH, Subramaniam A, Siveen KS, Perumal E, Samy RP, Bist P, Lim LH, Kumar AP, et al: Emodin suppresses migration and invasion through the modulation of CXCR4 expression in an orthotopic model of human hepatocellular carcinoma. PLoS One 8: e57015, 2013.

19. Yim H, Lee YH, Lee CH and Lee SK: Emodin, an anthraquinone derivative isolated from the rhizomes of Rheum palmatum, selectively inhibits the activity of casein kinase II as a competitive inhibitor. Planta Med 65: 9-13, 1999.

20. Lee HZ: Protein kinase $\mathrm{C}$ involvement in aloe-emodin- and emodin-induced apoptosis in lung carcinoma cell. Br J Pharmacol 134: 1093-1103, 2001.

21. Su YJ, Tsai MS, Kuo YH, Chiu YF, Cheng CM, Lin ST and Lin YW: Role of Rad51 down-regulation and extracellular signal-regulated kinases 1 and 2 inactivation in emodin and mitomycin C-induced synergistic cytotoxicity in human non-small-cell lung cancer cells. Mol Pharmacol 77: 633-643, 2010.

22. Lu Y, Zhang J and Qian J: The effect of emodin on VEGF receptors in human colon cancer cells. Cancer Biother Radiopharm 23: 222-228, 2008.

23. Zhang L, Chang CJ, Bacus SS and Hung MC: Suppressed transformation and induced differentiation of HER-2/neu-overexpressing breast cancer cells by emodin. Cancer Res 55: 3890-3896, 1995.

24. Menendez JA, Vellon L, Colomer R and Lupu R: Pharmacological and small interference RNA-mediated inhibition of breast cancer-associated fatty acid synthase (oncogenic antigen-519) synergistically enhances Taxol (paclitaxel)-induced cytotoxicity. Int J Cancer 115: 19-35, 2005.

25. Lacroix M and Leclercq G: Relevance of breast cancer cell lines as models for breast tumours: An update. Breast Cancer Res Treat 83: 249-289, 2004.

26. Little JL and Kridel SJ: Fatty acid synthase activity in tumor cells. Subcell Biochem 49: 169-194, 2008.

27. Li P, Tian W and Ma X: Alpha-mangostin inhibits intracellular fatty acid synthase and induces apoptosis in breast cancer cells. Mol Cancer 13: 138, 2014.

28. Yang YA, Han WF, Morin PJ, Chrest FJ and Pizer ES: Activation of fatty acid synthesis during neoplastic transformation: Role of mitogen-activated protein kinase and phosphatidylinositol 3-kinase. Exp Cell Res 279: 80-90, 2002.

29. Yellen P and Foster DA: Inhibition of fatty acid synthase induces pro-survival Akt and ERK signaling in K-Ras-driven cancer cells. Cancer Lett 353: 258-263, 2014.

30. Menendez JA and Lupu R: Oncogenic properties of the endogenous fatty acid metabolism: Molecular pathology of fatty acid synthase in cancer cells. Curr Opin Clin Nutr Metab Care 9: 346-357, 2006. 
31. Menendez JA, Vazquez-Martin A, Oliveras-Ferraros C, Garcia-Villalba R, Carrasco-Pancorbo A, Fernandez-Gutierrez A and Segura-Carretero A: Analyzing effects of extra-virgin olive oil polyphenols on breast cancer-associated fatty acid synthase protein expression using reverse-phase protein microarrays. Int J Mol Med 22: 433-439, 2008.

32. Rashid A, Pizer ES, Moga M, Milgraum LZ, Zahurak M, Pasternack GR, Kuhajda FP and Hamilton SR: Elevated expression of fatty acid synthase and fatty acid synthetic activity in colorectal neoplasia. Am J Pathol 150: 201-208, 1997.

33. Ogino S, Nosho K, Meyerhardt JA, Kirkner GJ, Chan AT, Kawasaki T, Giovannucci EL, Loda M and Fuchs CS: Cohort study of fatty acid synthase expression and patient survival in colon cancer. J Clin Oncol 26: 5713-5720, 2008.

34. Zhan Y, Ginanni N, Tota MR, Wu M, Bays NW, Richon VM Kohl NE, Bachman ES, Strack PR and Krauss S: Control of cell growth and survival by enzymes of the fatty acid synthesis pathway in HCT-116 colon cancer cells. Clin Cancer Res 14 5735-5742, 2008.

35. Shiragami R, Murata S, Kosugi C, Tezuka T, Yamazaki M, Hirano A, Yoshimura Y, Suzuki M, Shuto K and Koda K: Enhanced antitumor activity of cerulenin combined with oxaliplatin in human colon cancer cells. Int J Oncol 43: 431-438, 2013.

36. Murata S, Yanagisawa K, Fukunaga K, Oda T, Kobayashi A, Sasaki R and Ohkohchi N: Fatty acid synthase inhibitor cerulenin suppresses liver metastasis of colon cancer in mice. Cancer Sci 101: 1861-1865, 2010.

37. Li JN, Gorospe M, Chrest FJ, Kumaravel TS, Evans MK, Han WF and Pizer ES: Pharmacological inhibition of fatty acid synthase activity produces both cytostatic and cytotoxic effects modulated by p53. Cancer Res 61: 1493-1499, 2001.
38. Notarnicola M, Pisanti S, Tutino V, Bocale D, Rotelli MT, Gentile A, Memeo V, Bifulco M, Perri E and Caruso MG: Effects of olive oil polyphenols on fatty acid synthase gene expression and activity in human colorectal cancer cells. Genes Nutr 6: 63-69, 2011.

39. Zhang C, Teng L, Shi Y, Jin J, Xue Y, Shang K and Gu J: Effect of emodin on proliferation and differentiation of 3T3-L1 preadipocyte and FAS activity. Chin Med J (Engl) 115: 1035-1038, 2002.

40. Ma YS, Weng SW, Lin MW, Lu CC, Chiang JH, Yang JS, Lai KC, Lin JP, Tang NY, Lin JG and Chung JG: Antitumor effects of emodin on LS1034 human colon cancer cells in vitro and in vivo: Roles of apoptotic cell death and LS1034 tumor xenografts model. Food Chem Toxicol 50: 1271-1278, 2012.

41. Kim J, Lee JS, Jung J, Lim I, Lee JY and Park MJ: Emodin suppresses maintenance of stemness by augmenting proteosomal degradation of epidermal growth factor receptor/epidermal growth factor receptor variant III in glioma stem cells. Stem Cells Dev 24: 284-295, 2015.

42. Chuang HY, Chang YF and Hwang JJ: Antitumor effect of orlistat, a fatty acid synthase inhibitor, is via activation of caspase-3 on human colorectal carcinoma-bearing animal. Biomed Pharmacother 65: 286-292, 2011.

43. Wang HQ, Altomare DA, Skele KL, Poulikakos PI, Kuhajda FP, Di Cristofano A and Testa JR: Positive feedback regulation between AKT activation and fatty acid synthase expression in ovarian carcinoma cells. Oncogene 24: 3574-3582, 2005.

44. Liu X, Shi Y, Giranda VL and Luo Y: Inhibition of the phosphatidylinositol 3-kinase/Akt pathway sensitizes MDA-MB468 human breast cancer cells to cerulenin-induced apoptosis. Mol Cancer Ther 5: 494-501, 2006. 